\title{
"We Are Always After That Balance" - Managing Innovation in the New Digital Media Industries
}

\author{
Sabine Hotho, Katherine Champion'
}

\begin{abstract}
The pressure to innovate is growing as technology cycles change more rapidly. Organisations need to balance exploration and exploitation effectively if they are to heed the innovation imperative. Organisational ambidexterity is proposed as a means to achieve such balance with structural or contextual ambidexterity as possible choices. Yet how organisations become ambidextrous is an as yet under-researched area, and different industry sectors may pose different innovation challenges. Using the case study method, this paper examines how a computer games company responds to an industryspecific innovation challenge and how it endeavours to balance exploration and exploitation. The findings suggest that ambidexterity is difficult to achieve, and is fraught with organisational tensions which might eventually jeopardise the innovation potential of a company. The paper suggests that more qualitative research is needed to further our understanding of innovation challenges, innovation management and organisational ambidexterity.
\end{abstract}

Key words: ambidexterity: innovation management; creative organisation; exploration and exploitation.

\footnotetext{
I Dundee Business School, University of Abertay Dundee, Dundee, DDI IHG, Scotland, United Kingdom. Tel.: 0044-I382-308259. E-mail: s.hotho@abertay.ac.uk
} 


\section{Introduction}

Pressures on businesses large or small to innovate are growing as technological and scientific developments accelerate (Quinn, Baruch, Zein, 1997; Bilton, Cummings, 2010; Isaksen, Tidd, 2006). Where previously innovation was the domain of a separate R\&D function, innovation management today recognises the need for businesses to engage in both efficiency focused and new value creating innovation (Hoogstraten, 2005; Kim, Mauborgne, 2004). Existing markets are served through incremental innovations that exploit competences, capabilities and technologies. New markets and products are created through explorative resource deployment and experimental innovation activities that stretch existing or require new capabilities (March, I99l; He, Wong, 2004; Güttel, Konlechner, 2009). While competitive advantage depends on both types of innovation capability, longterm success depends on the organisation's ability to handle exploitation and exploration activities equally effectively (Collins, Porras, 1997; March, 1991). Those who achieve this are ambidextrous organisations (Gibson, Birkinshaw, 2004; Raisch et al., 2009; Tushman, O’Reilly, 1996).

Evidence confirms the positive relation between ambidexterity and long-term profitable growth (O’Reilly, Tushman, 2007; Tushman, O’Reilly, 1996). In practice most firms gravitate towards monodexterity as being less effortful or resource intensive (Güttel, Konlechner, 2009). But while delivering on short-term advantage, the long-term consequence might be reduced innovation capability. How to achieve an effective balance between exploration and exploitation, how to become and remain ambidextrous, is thus of particular importance in fast-paced high technology sectors. One such sector is the computer games sector. A rapidly changing, still young industry, it is recognised as making significant contributions to economic growth, regional development and high value employment creation (NESTA, 2008; EKOS, 2009). The business creation rate is high, but so is the business failure rate among the micro- and small businesses that are predominant in this industry (Chaston, 2008; dePeuter, Dyer-Witheford, 2010). Often enough these businesses fail where they prioritise games development designed to generate intellectual property (exploration-focused monodexterity; SET Interviews, 2010). Given the longterm economic (and cultural) relevance of this sector (Chatfield, 2010), it seems timely to address how small computer games companies strive for the balance between exploration and exploitation, how they search for ambidexterity and what management issues they may confront as they do so. To further such insight requires a process perspective.

Process research of ambidexterity to date has focused on sequential choices between design options (Raisch, 2008), Senior Management Team (SMT) choices (Tushman, O'Reilly, 1997; O'Reilly, Tushman, 2007), or life cycle stages (Güttel, Konlechner, 2009). Process research that addresses issues of emerging (succeeding or failing) ambidexterity and associated conflicts that might surround such process is lacking. This is partly a consequence of the fact that ambidexterity research mostly takes the business, firm or SMT as its unit of analysis and privileges quantitative methods, resulting in an under-socialised discussion of ambidexterity and a conceptualisation of ambidexterity as a managerial choice between structural options, rather than a process involving human interaction. Thus our understanding of how the balancing act between exploitation and exploration is decided upon, enacted or contested in organisational reality is still limited. Given the social proximity between management (team) and employee in the SME context, this is an area of particular research interest that will add significantly to our understanding of ambidexterity.

This paper explores how the case company addresses and realises the challenge of exploration and exploitation, how, and to what extent, ambidexterity is recognised, and how balancing decisions between exploration and exploitation affect the organisational 'climate' of the company. Specifically we argue that industry imperatives might hinder the appreciation of balancing exploitation and exploration, and that sustaining the creative climate that is required for either, produces organisational conflicts, and unanticipated management challenges which may ultimately jeopardise the organisation's innovation capability. Given the exploratory nature of the study, we propose that significantly more qualitative and process research is required to further our 
understanding on the difficulty of innovation management as the management of creative people pursuing exploration and exploitation equally, if differently 'creative'.

The paper is structured as follows: the next two sections review the ambidexterity and (briefly) creative organisation literatures to identify relevant themes for data analysis. A brief section outlines specific innovation challenges of the digital media industry. The remainder of the paper presents case study findings and a discussion of the findings, their scope and limitations.

\section{Managing Innovation - The Challenge of Ambidexterity}

Exploration and exploitation are contradictory modes of operation, learning, managerial and strategic logic (March, 1991). Ambidextrous organisations are capable of balancing these conflicting tensions successfully (Birkinshaw, Gibson, 2004; Jansen et al., 2005; Isaaksen, Tidd, 2006), equally capable of performing explorative and exploitative innovation activities, of alignment and adaptation (Tushman, O’Reilly, 1996; Benner, Tushman, 2003; Birkinshaw, Gibson, 2004). Ambidexterity is vital to sustained organisational success as the unbalanced focus on exploitation may lead to organisational inertia, resource lock in, loss of learning capability, and failure (Nadler, Tushman, 1996). Similarly, over-emphasis on exploration will prevent the organisation from development, testing and embedding those routines that are required for operational effectiveness, variance reduction or increased productivity (O'Reilly, Tushman, 2007).

While the case for ambidexterity is well established, organisations gravitate towards exploitation because of managerial short term bias (O’Reilly, Tushman, 2007) and because of the risks, uncertainties and managerial efforts required for exploration (March, 1991; Noteboom 2000). In contrast, creative industries privilege exploitation as reputation, brand and artistic value creation imperatives override commercial imperatives (Bilton, 2007).

Studies examining whether organisations follow patterns of exploration/exploitation, how they become either ambidextrous or monodextrous are rare. Some argue that young organisations are ambidextrous 'by default' before they become monodextrously exploitative (Güttel, Konlechner, 2007; 2009), and that returning to a state of ambidexterity is complex and costly (Siggelkow, 200I). As organisations mature, they focus increasingly on routines of standardisation (Güttel, Konlechner, 2007; 2009), exacerbated by path dependency (Teece et al., 1997; March, 1991). The assumption is that this applies to most, if not all industries.

Studies relate relative levels of ambidexterity and innovation to senior management team characteristics and their relative dynamic capability to sense market opportunities, and recombine, reconfigure, or obliterate, resources to align or adjust to external change (Brown, Eisenhardt, 1997; Teece, 2006; O’Reilly, Tushman, 2007). Theoretically, this makes innovation management an ongoing change management task. Reconfiguration, for instance, results in resource reallocation which in turn is likely to trigger power contests or change resistance (Edwards, et al., 2005). The ambidexterity literature remains silent on this. We thus agree with Edwards et al. who suggest a process perspective of innovation that includes these dimensions (Edwards, et al., 2005), in order to develop an understanding of how management and employees experience, enact and contest innovation (Barnett, Storey, 2000, in Edwards et al., 2005) and make sense of processes such as shifts between exploration and exploitation.

How organisations should balance exploration and exploitation is still an open debate, arranged around either/or choices (Raisch, 2008). Whether organisations should pursue exploration and exploitation sequentially or simultaneously is discussed in the context of the punctuated equilibrium versus incremental change literature, with the former arguing that any form of breakthrough innovation - defined as innovation of central impact on the organisation - can only be achieved in 'revolutionary' periods of both external and internal radical change (Tushman, O'Reilly, 1996; Brown, Eisenhardt, 1997), followed by stable periods of incremental improvement (exploitation). Ambidextrous organisations would be able to switch between modes of innovation, alternating exploitation and exploration over time. Alternatively, continuous adaptation is argued as less disruptive, thus resulting in long-term superior 
results and the simultaneity of exploration and exploitation is considered to be a "crucial capability for survival" (Brown, Eisenhardt, 1997: I). This requires a fluidity of structures, semi-structures and tight-loose coupling, arguably a more complex management challenge than any alternating mode but enabling the co-evolution of distinct innovation streams (O'Reilly, Tushman, 2004). Such simultaneous exploration and exploitation is enabled through dual structure arrangements or structural ambidexterity which refers to the structural, physical and spatial separation of units tasked with either exploration or exploitation (Gibson, Birkinshaw, 2004; O'Reilly, Tushman, 2007).

In fast changing environments, the case for simultaneous structural ambidexterity has been made (Güttel, Konlechner, 2009; O'Reilly, Tushman, 2007). Yet structural ambidexterity requires significant integration and reintegration efforts to mitigate against the risk of isolation, and, above all, strategic shifts as organisations 'switch between' modes (Raisch, 2008). More recently, an interest in contextual antecedents of organisational ambidexterity has thus emerged, in part because dual structures are not 'an ideal solution'. Gibson and Birkinshaw explore and propose contextual ambidexterity as an alternative (Gibson, Birkinshaw, 2004). Contextual ambidexterity locates ambidexterity in individuals' activities and action rather than in dual structures. It relates to an organisation's ability to foster and integrate both explorative and exploitative activities as deliberate choices made by individual employees, enabled to make such choices through the organisational climate and context facilitated by senior managers (Gibson, Birkinshaw, 2004). Birkinshaw and Gibson's contribution defines employees as agents of ambidexterity and thus innovative capability as they "take the initiative and are aware of opportunities beyond their own jobs" (Birkinshaw, Gibson, 2004: 9).

Mangers of innovation must thus facilitate an organisational climate conducive to ambidextrous mindsets and behaviours encouraging (explorative and exploitative) innovation. Goshal and Bartlett (1997) identified stretch, discipline, support and trust as features of such organisational context, combined with processes and systems that encourage employees to "make their own judgements about how to divide their time between conflicting demands for alignment and

ISSN: 07I8-2724. (http://www.jotmi.org)

Journal of Technology Management \& Innovation (C) Universidad Alberto Hurtado, Facultad de Economía y Negocios adaptability" (Gibson, Birkinshaw, 2004: 21I). These contextual determinants resonate with the literatures that concern the management of high performance knowledge workers, and of their creativity that lies, inescapably, at the core of all innovation, to the extent that they articulate dimensions of performance management (discipline, stretch) and social context (support, trust) as comprising the innovation and ambidexterity-conducive organisational context (Bolinao, 2007). Discipline and stretch refer to mechanisms, systems and processes inducing workers to strive to meet all expectations through clear standards of behaviour and performance, consistent and effective feedback, and to strive beyond those expectations through shared ambitions, visions, identity and purpose. Support and trust relate to attributes facilitating trust, openness, fairness, with managers acting as facilitators rather than controllers, autonomy, risk and experiment, and discretion (Goshal, Bartlett, 1997; Gibson and Birkinshaw, 2004; Bolinao, 2008). These dimensions combine 'hard' and 'soft' and are at the disposal of an SMT wishing to create the 'ambidextrous organisation' the creative organisation in other terms.

Güttel and Konlechner (2009) observe that the ambidexterity literature has not sufficiently focused on "how (especially contextual) ambidexterity is achieved and under which circumstances it is successful" - or otherwise (Güttel, Konlechner, 2009: I54). We propose that a link between the ambidexterity literature and the literature of creativity management might provide a way forward and in particular in the context of new creative industries.

\section{Managing Creativity for Innovation - Facilitating Ambidexterity?}

Innovative organisations are dependent on the knowledge, skills and creativity that reside in their employees (Cummings, Oldham, 1997). This requires work practices, structures and processes which are radically different from industrial age forms of organising work (Baron, 200I; Ehin, 2008; Bilton, 2007; Bilton, Leary, 2002; Mumford, 2000).

Networked structures around self organising teams and projects, devolved decision making and flatter lines of communication are defining features of organising for knowledge creation (Bilton, 2007; Simon, 2006). Task 
autonomy is seen as vital to creating a work environment that supports creativity and innovation (Cummings, Oldham 1997; Nonaka et al., 2000) as much as to intrinsic motivation and job satisfaction. It relates to the individual as well as self-organising teams that multiply divergent thinking (Nonaka et al., 2000).

Other factors that facilitate creativity and innovation include time and in particular "trust time" (Randle, Rainnie, 2007: 32), buffering against commercial pressures and client requests, structural separation for the purpose of explorative innovation, encouragement of risk, a permissible attitude to failure, and slack (Mumford, 2000). Rewarding creative or knowledge work requires feedback and reward that focuses on work and the process of creative idea generation rather than outcomes (Mumford, 2000; Stenmark 2000) and the suggestion is even made that financial, i.e. extrinsic, rewards may be counterproductive (Stenmark, 2000). If risk and exposure to critique or failure are part of the creative process, supportive teams and supportive supervision are paramount to maintaining levels of confidence and trust (Amabile et al., 1996; Oldham, Cummings, 1996), as is the supportive team structure (Amabile et al., 1996). To be successful innovative companies are further advised to engage their employees in processes such as adventuring, exploring uncertainty, incremental risk taking, conceptual and contextual confronting (Andriopoulos, Lowe, 2000). Such activities enhance organisations' capability to remain responsive to arising opportunities. They require fluid and expressive modes of communication.

Creativity research agrees with these premises. Amabile et al. (1996), and similarly Ekvall (1996), integrate most of the work practices above within a conceptual model of the creativity-conducive organisational climate. Relative levels of organisational, supervisory and team encouragement of creativity, autonomy and the relative sense of ownership flowing from that, resource availability, the balance of positive (task complexity related) and external pressures and constraints combine to create an organisational climate that is the prerequisite for creative work and innovation (Amabile et al., 1996). This is akin to Cummings' notion of the creative organisation as featuring relatively small degrees of formalisation, flexibility, task discretion, flat structures, discretion, open communication, intrinsic needs-based reward systems, flexible work structures and self selection mechanisms (Cummings, 1965).

The practices and context features of the 'creative organisation' overlap with the characteristics of contextual ambidexterity where discipline relates to creating an environment in which individuals voluntarily strive to achieve and perform, where feedback is open and candid and consistent, where ambitions are stretched and shared, supportive behaviours are fostered and facilitated, resources are freely available for experimentation, initiative and new idea generation is encouraged, and trust is the basis of decision making and work (Gibson, Birkinshaw, 2004). And managers are facilitators rather than controllers, brokers rather than rule makers (Bilton, Leary, 2002; Bilton, 2007). Brokers set the boundaries for the creative process (Boden, 1994) and confine creative activity ultimately within commercial imperatives. This creates the space for creativity within which freedom reigns, but it is managerially controlled. Brokering and facilitating, not command and control become the value-adding role of managers who transform creative people into ambidextrous employees who engage "in both exploitation-oriented [...] and exploration-oriented actions" (Gibson, Birkinshaw, 2004) seamlessly, thus finally resolving the innovation dilemma. But to what extent real organisations as sites of social interaction can measure up to this ideal type needs to become a more central concern of the ambidexterity and creative organisation literature.

\section{From Ideal Type to Reality - An Industry-Specific Innovation Imperative?}

In the computer games industry the dilemmas of innovation versus organisation, exploration versus exploitation, autonomy versus control are particularly pronounced as the expectation of creativity and innovation are deemed the most defining feature of the industry and the career identities constructed therein (Christopherson, 2004; Cadin et al., 2006). The balancing act between the opposing poles of design and utility is particularly challenging as technology life cycles are getting shorter, technology innovations are potentially disruptive, and existing business opportunities, business models and the supporting organisational arrangements can rapidly become 
outdated (ibid.). Time pressure to go to market is high and time as a resource normally scarce. Yet there is an expectation that artistic sophistication is the true source of value creation. This poses a particular innovation dilemma.

Game development is risky and the commercial success of a game under development is uncertain (Banks et al., 2002). Even where revenue streams are generated by commercial games developed to client specifications, i.e. work for hire (WFH) and are sufficient to create finance for explorative innovation activity, the commercial and financial constraints for small studios are significant. Yet 'doing nothing' is not an option. The expectation that games developers should aim for the creation and eventual exploitation of Intellectual Property (IP) work and consequently devote resources to higher value IP creation through explorative innovation is widely held among industry players, agencies, policy makers, present and future employees, and customers (Christopherson, 2004). It is a factor sensitively related to competitiveness in the global market (EKOS, 2009), and, internally, to the retention of those employees who create such value. Shifting to IP creation requires strategic shifts at some stage that involve either experimentation with flexible organisational forms, increase in workforce, a total shift from commercial to IP work, or structural arrangements designed to enable explorative and routine activities simultaneously. These structural and organisational demands reflect the conflicting tensions between exploration and exploitation in particularly sharp profile. Computer games developers share the "innovator's dilemma" of having to strike the balance between exploration and exploitation (Edwards et al., 2005: 1122; Nooteboom, 2000), but this challenge is exacerbated in an industry with a fast-paced, pronouncedly creative and technology-driven innovation imperative. A games developer pursuing WFH (exploitation) will successfully build up a portfolio but at the price of dynamic capability (Tushman, O'Reilly, 1996). Yet without such capability for adaptation the businesses will not be able to sustain such growth as technology cycles shorten and routes to market change. Organisational ambidexterity, i.e. the ability to engage in both exploitation and exploration, seems thus of particular importance for this industry (Raisch, 2008; Raisch et al., 2009). How to develop such dynamic capability and how to manage it has not yet been addressed in this industry sector.

Work organisation is project based, organised around short term production activities which have a defined deadline, and production specifications set either by the client or by the company's artistic aspirations (Christopherson, 2004). Organisational forms are temporary, and the workforce is required to readjust continuously to new project team configurations. In small businesses this is a particular challenge as team selection is limited by resource constraints (Christopherson, 2004). Adaptive networks (Antcliff et al., 2005), flexible, temporary and casual employment arrangements and internal and external project work are among the defining characteristics of the sector (Beck, 2003; Grabher, 2004; Sydow, Staber, 2002), used in part to sustain a required level of responsiveness and innovativeness and to protect the company's independence. Typically the owner-manager will select the structure deemed most appropriate for the business. What links these structural experiments is the requirement, consistent with Nooteboom (2000), to recognise that "exploitation requires maintenance of existing identity, knowledge and practice, with a certain amount of control and co-ordination, in a dominant design" whereas exploration "requires their change, with a loosening of control and co-ordination" (Nooteboom, 2000: 8).

Computer games companies experiment with forms of 'ambidextrous organisation' (Zackariasson, Wilson, 2007; SET Interviews 2010). Alternating between exploration and exploitation seems one frequently tried pattern, as companies need to build up revenue through WFH (exploitation) before they can invest in IP (exploration). This would require organising for exploitation before organising for exploration. But young organisations in this sector must also be simultaneously ambidextrous and creative with it because they are young companies and in an industry where it is their innovativeness that will attract clients prepared to fund development upfront. To that extent ambidexterity, arguably, is both a necessity and a nearimpossibility for such companies, and becoming (let alone remaining) ambidextrous may be a particular challenge for organisations in this industry. 


\section{The Case Company}

The case company CCC is a small independent development studio established in 2000. The company had an SMT comprising the MD and four senior members, and a workforce of ca 20 artists, developers and coders. At the time of the research the company had taken the decisive strategic step of moving from WFH to IP (exploitation to exploration), and was several months into this change. This had generated substantial changes to the organisation of work. While previously work had been organised around small shortlife projects with each project team member executing his respective specialism, the company now worked exclusively on two self-funded games developed by two larger teams, working with more ambiguous outcome specifications, and a less certain timeline. Client specifications had been replaced by a single artistic vision and quality standards controlled by one member of the senior team. The company was thus in a process of change typical for the industry in (a). pursuing IP work as a prime strategic objective, (b). managing this as a change process from commercial to creative work, and efficiency focus to exploratory focus, and (c). selecting from a range of options the structures and work arrangements to MD considered most appropriate to achieve the IP related objectives.

\section{Methodology}

We have chosen the case study approach as best suited for a process-oriented explorative study (Flyvbjerg, 2003; Hakim, 1994; Patton, Appelbaum, 2003; Yin, 1994, 2009) as it generates in-depth reflexive data that capture the complexity and plurality of organisational perspectives (Patton and Appelbaum, 2003). Given the current stage of ambidexterity research, and the need to tie this more specifically with literatures that forefront contextual dimensions shaped in specific organisational settings and interactions, an exploratory case study can be utilised to open new directions, or develop pertinent propositions for further inquiry or to explore existing theories (Kaarbo, Beasley, 1999; Yin, 1994). The present case study serves the purpose of extending currently under-socialised studies of ambidexterity and innovation by emphasising the process of becoming.
A concern about the value of case study research is scientific generalization from a specific case (Yin, 1994). The generalisability of case studies can be increased by their strategic selection and the relevance and typicality of the present case reflects this. To that extent this study matches the requirements for a representative single case study as discussed by Yin (Yin, 2009). Further, as required for case study designs, triangulation, the synthesis of data from multiple sources, was attained through multiple data sources and contexts, stages of analysis, and researchers involved, which maximises the robustness of the study and the confidence of its conclusions (Bryman, 2004; Cresswell, Plano Clark, 2007; Denzin, Lincoln, 2008).

The data for the study was collected over a period of 8 months. Rich qualitative data was generated from semistructured interviews with the managing director and the senior management team, observations of meetings and staff interviews, producing multiple perspectives on change. These interviews were held at periodic intervals and were consistently structured around the key dimensions of the organisation, namely strategy, structure, culture, work organisation, to capture the shifting interactions and relations in the organisation. In addition, researchers attended and recorded in-depth interviews conducted by the HR officer with key staff which combined questions the senior team deemed relevant as it faced transition issues, and questions generated by the researchers as they analysed organisational changes. SMT reflections on these staff interviews were also recorded, generating the 'later stage' data of the project. These data were complemented by data generated from semi-structured interviews with employees in 2007 (Hotho, Haubrock, 2009). Additional data sources were company literature, company value statements and web presentations. Further, five in-depth interviews with MDs of comparable studios were conducted separately to confirm the researchers' understanding of 'typical events' in the industry, and for further triangulation.

Data were transcribed immediately after the interviews and the researchers identified and classified recurring themes separately and then compared these. As described by Strauss (1987) the data analysis commenced immediately with the first interview, and the observations and questions raised informed the 
categorisation of findings and the choice of further questions. The data were analysed using thematic coding (David, Sutton, 2004; Coffey, Atkinson, 1996; Strauss, 1987) to explore how the key aspects of innovation and change imperatives were present and seen as changing. Coding used categories of both in vivo and socially constructed codes i.e. those developed from the terms used by the participants themselves and those based on the researchers' existing knowledge and frame of reference. This aided both simplification, through reduction to dominant categories, and also complication through an expansion and reconceptualisation of the data (David, Sutton, 2004; Coffey, Atkinson, 1996). Within the analysis stage the emphasis has been on a holistic approach to explanation with an aim to think reflexively and critically about how the researchers' view of the world may have shaped their assumptions of the findings (Mason, 2002). This has helped promote the visibility of social processes situating the research within a real world context (Denzin, Lincoln, 2008).

For the purpose of this paper, data are summarised under the following themes or headings:

Towards understanding ambidexterity

Exploring ambidexterity

Choosing between exploration and exploitation

Exploration - the upper hand

Organisational climate - not so conducive to contextual ambidexterity?

The following summarises the findings, with quotes from interviews in italics.

\section{Findings}

\section{Towards Understanding Ambidexterity}

The company had deliberately pursued an 'exploitation' strategy through focusing on WFH for the first few years of its existence. This was presented as a rational strategic decision designed to generate the resources required for IP as the riskier yet more rewardingly 'creative' work all company members wished to engage in: The previous phase was about profitability to feed back to invest in creative new games.
At that stage the company deliberately worked more as a production house producing products, it was more about generating income than value. The exploitation phase was seen as a necessity but not the desirable mode as all aspired to producing our own IP. Processes and systems were put in place by SMT which allowed the effective, high quality production of games for the client, on clearly timed and predictable project schedules. Employees worked in small teams, and with predictable routines. Management effort concentrated on operational effectiveness and clear procedures as essential if the long-term goal to produce the wow game we want to play was to be achieved. Employees seemed to accept the necessity as their own enthusiasm for games and the prospect of eventually doing IP work kept them motivated. Exploitation was endured as a means to a higher end. There was clear evidence of discipline, i.e. of "hard elements" (Gibson, Birkinshaw, 2004: 213), but little of balance and what seemed to prevent "disillusionment among employees" (ibid.) was (a). their inherent passion for games, and (b). the prospect of doing WFH for the ultimate vision of IP.

The need for ambidexterity was emerging as a need shared by SMT and employees, but quite consistently in terms of sequencing or alternating between exploitation to bring in the money and exploration for reputation and IP. Importantly, there was a reflection on the need for increasing and the fear of losing innovative capability. Senior managers and employees reflected on the adverse impacts of routine work as their level of innovativeness seemed to decline: senior managers remarked on atrophy setting in as the company became ever more successful at work for hire, whilst employees observed that they were becoming dozy old men. The bulk of the company was used to doing what needed to be done, it was fairly tightly controlled by the architect. They got used to doing what needed to be done ... everybody just got ... weak. The company thus realised the need to build up the company's ability to remain innovative and creative whilst producing income for explorative innovation. This could be described as an emerging understanding of the need for ambidexterity: We weren't developing as such. We were doing the same thing over and over which was great for earning money, but not good for the future of the company. 


\section{Exploring Ambidexterity}

To address this atrophy the company had already put in place mechanisms to encourage the production of new ideas such as trust time, and formalised pitches that encouraged employees to present new ideas for games with potential for IP. This was a cherished yet eventually routine mechanism in the eyes of some employees and eventually a meaningless ritual in the eyes of senior managers. It produced good ideas, but was not consistently managed: We tried to give people space and time to develop creatively ideas that the company could sell and it did not work. Management's response was to withdraw the mechanism and restructure into a separate development unit (we had to put these people into isolation) but this too was abandoned. The need for a more holistic approach to managing innovation through fostering a creativity-conducive climate (contextual ambidexterity) seemed to be gradually emerging as senior managers reflected on realising the importance of integrating values to confirm the vision of the company, of providing leadership rather than management skills, and of focusing on the development of soft rather than hard skills. The company now wanted to reinforce shared values, vision and identity through soft mechanisms, and effort to embed these values were undertaken. In theory this should contribute to a climate conducive to innovation and creativity - in practice the efforts could not be sustained because this development effort was undertaken in parallel with embarking on the next phase of the company's activity - the move to IP.

Choosing between Exploration and Exploitation Monodextrous, Ambidextrous?

The conversations reiterated exploration and exploitation primarily as alternating choices rather than as simultaneous modes, and exploitation subservient to exploration. The company had experimented with simultaneous structural forms of ambidexterity. The structural ambidexterity phase was relatively short-term and involved the creation of an internal dual structure with a small development and numerous small game production teams doing external stuff. The reasoning behind this was partly to motivate and retain core senior staff, partly to push IP work. It was eventually abandoned.
Exploration (IP work) eventually replaced all other structural experiments. At the time of our interviews the company had moved to exclusively IP work, in reaction to opportunities the SMT team had sensed and seized in the market. The company's innovation trajectory had thus been one from exploitation to (briefly) dual structures to exploration. Simultaneous dual structures had served as incubator that effectively isolated a limited number of innovators and once their efforts became tangible dual structures were replaced by an exploration-only focus. It was at this stage that tensions emerged in the company. Specifically, if at this stage a capability for contextual ambidexterity was to be sustained, significant management effort would be needed to balance the conflicting demands of risk and experimentation on the one hand, commercial survival on the other. This effort was not invested, as the management of exploration consumed management 'energy'.

\section{Exploration - The Other Hand}

The move to IP was opportunity driven and resource reconfiguration a sudden challenge, not an anticipated change. Interviewees reflected on the changes with ambivalences, conflicting emotions such as disappointment, and frustration. SMT members regretted that there had been no transition phase, that they had jumped too quickly but felt that they had no option, indicating a lack of preparation for exploration. From the start the change to IP felt problematic, and there was a sense of - paradoxically - having lost something. While there was a perception of freedom, the pressure on the company also increased: IP work had to be brilliant and something to be proud of as the company's reputation was at stake. This created enormous pressure for the SMT, and employees. SMT saw resulting tensions as a reflection on the inadequacy of the development teams and expressed genuine disappointment, frustration that the team did not have the understanding of what they were required to do. At issue was attitude: We can't do our job with that kind of attitude. The company seemed to separate into pivotal people who buy into the values and 50 maybe $60 \%$ who do not. Midway through the change phase one senior member conceded that he had given up on trying to convert people. Where previously values were seen as effecting cohesion, the company now seemed 
split into separate (more or less capable) groups. Management seemed to withdraw from the effort of managing all 'creatives' around company aspirations and objectives and settled into accepting that IP work had polarised their development resource. Retrospectively SMT conceded a lack of focus on balance and development of skills and capabilities was conceded.

Such ambivalences became ever more pronounced over time. Earlier the senior team had expressed confidence that the shift to IP had increased the opportunity for innovation and artistic expression because, so the MD, I have now delivered a deal that allows the team to make the game they want. But the increased risk increased the pressure on the team to deliver: If they fail I would not trust them next time round. It seemed that the distance between management and employees widened as tolerance for failure was replaced by an emotional pressure on employees not to disappoint.

IP generation was far more challenging to the team, and whilst liberating also stressful as the internal benchmarks for quality including creative solutions had been raised: the motivating cycle of satisfaction associated with short WFH had been lost and IP work did not yield the motivation boost all had anticipated. In part this was because of the dual function of IP work - liberating originality and innovative potential, whilst also being a commercial risk: the pressure of having to prove ourselves to the outside world ... showing that we can compete on contemporary releases pervaded all interviews. The pressure to create something the company can be proud was enormous as the company's reputation was seen as at stake. The potential for conflict between the creative and the commercial interests attached to IP work was thus a major issue.

SMT controlled this issue through ever more stringent explications of standards, processes and milestones. Repeatedly senior members emphasised the need to control any one particular agenda.

Employees, while initially embracing IP, had become strained, attributing much of their stress to time and resource pressures which became a source of disquiet between SMT and employees: having expected that the original stuff would be far more buzzing, they became soberly aware of the ramifications of failure. WFH was reflected on positively as a period where I was happy because there was freedom within constraints there was a kind of freedom. Repeatedly employees commented that something had been lost and levels of control had increased. Reduced levels of trust were reflected upon and were seen as gestures of further and unnecessary management control.

Employees experienced this shift as they felt strongly that the 'artistic vision' was much more controlled from the top, a one man one idea sort of thing behind design, and this was seen as a source for disaffection in particular amongst the artists whose career aspirations are more tied to what they want to do. In the view of some, opportunity for artistic expression was replaced by a visionary at the top and a mysterious opaque behind barriers kind of vision that left employees in the dark. This resulted in loss of commitment, as the single vision gave rise to the view that individuals' ideas were no valued as previously, and no feedback given: I think we have lost what it was that attracted me to the company.

\section{Organisational Climate - Not So Conducive to Contextual Ambidexterity}

The evidence cited so far culminates in a sense of a changed organisational climate: while the organisation had not been managed systematically for creativity and innovation there were clear signs of co-presence of performance-focused and social context focused, hard/soft, stretch and discipline/trust and support characteristics of the creative organisation (Amabile, et al. 1996), and thus the seeds for contextual ambidexterity - and arguably maintaining these through the difficult IP phase would have been paramount to sustaining the organisation's creative climate and potential for ambidexterity. But there was limited evidence of attempts to build on or deepen these into a balanced system, even as the company realised that the over-emphasis on efficiency had resulted in inertia. The company realised that exploitation had reduced capability for creativity and innovation in part because $a$ lot of the time you had to suppress your creative urges. But ultimately, the company switched between modes of monodexterity, and paradoxically with the result that as the company switched to IP work, the hard rather than the soft, and the stretch/discipline rather than autonomy/support, performance rather than social 
context dimensions of organisational context became more emphasised. This was realised by SMT as a necessity, and by employees as lack of trust and increased control.

Autonomy combined with control emerged as a central area of contention. At the early stage the change to IP work was presented by one SMT member as a significant opportunity for autonomy, and a sign that greater trust had been invested in employees, but soft goes with hard, and the emphasis on output control was sharp: this puts enormous pressure on the teams to deliver and to maintain the trust invested in them. Earlier the belief in people and their ability was strong. This changed over time and disappointment in the development resource which just isn't set up the way that we need it set in. The difficulties of making staff work autonomously yet to standard became a constant theme, and SMT located explanations for this in the teams rather than in its own approach. Employees struggled with new control systems and procedures such as daily updates as they declined to see their value: they don't see the value of these mechanisms and they don't believe that there are any consequences for not doing it. There was at times a sense of rebellion. Whilst SMT expected daily accountability, employees consciously chose not to do this. For SMT this seemed a lack of professionalism which undermined its confidence in the work force: all it does is undermine my confidence in us delivering anything. We can't do our job with that kind of attitude.

Eventually SMT's reflections on autonomy and the resultant trust to deliver, not just deliver something but something that is quantifiably CCC, i.e. being truly indicative of CCC's creative identity, became ambiguous though as the realisation set in that they might not have supported staff sufficiently, but modified again: we gave people opportunities to develop and they didn't. To be autonomous you have to prove yourself. Most people have not proven themselves. Autonomy during the WFH phase was described as an amazing illusion - people felt that they had more autonomy but that was intentional - it was a carefully controlled system.

Employees reflected on autonomy as central to their work satisfaction. WFH was now seen as affording much more autonomy, scope for decision making and expression, and once more some people feel we have lost autonomy as the many pressures made project leaders too controlling, there is too much reviewing and nitpicking. Where WFH left space for discretion, decisions were now taken at the top and filtered down as task lists. Significantly employees felt that previously there was more trust in people and their capabilities which they felt management had now lost, resulting in stricter control and loss of morale.

\section{Discussion}

At the end of the study CCC announced a reduction of its workforce and withdrew from IP work. The findings thus provide some support for two views: that ambidexterity is desirable, and that in practice it is difficult to achieve let alone maintain. The innovation challenge, as shared by SMT and employees, was realised as an alternation between modes of exploitation and exploration, rather than simultaneous ambidexterity which would require a more stringent balancing of the two innovation/activity streams and its supporting context. Whilst SMT demonstrated in their sensing and seizing two prerequisites for ambidextrous organisation, their reconfiguration capability was limited as it seemed reactive rather than proactively prepared for (Teece, 2006). Further, in practice there was overemphasis on the efficiency of exploitation, albeit as a means to an end, rather than on the attempt to balance organisational ambidexterity. Where this happened it was short-lived.

The study confirms the tendency of organisations to gravitate towards monodextrous activity (Güttel, Konlechner, 2009). The need for alternation between exploitation and exploration is recognised as essential to mitigate either against organisational inertia - keenly felt in CCC - or against the competency trap (Miller, 1993; Liu, 2006; Isaksen, Tidd, 2006), and as a motivation strategy - a view shared by all. But there was limited evidence of an appreciation of the complementary nature of balancing exploration and exploitation as equally, if differently, valuable domains of activity - exploitation was seen as a stage to be ultimately 'left behind' rather than a dualism (Isaksen, Tidd, 2006). The need for the ability to "play two games at once" (Isaksen, Tidd, 2006: 42) is "clear but daunting" (Tushman, O'Reilly, 1997: 14), and the very difficulty of 
conceiving, conceptualising and implementing ambidexterity may explain its absence here as elsewhere. The case company had 'flirted with' ambidexterity but neither knowingly nor consistently. Interestingly, the focus in the case company was on experimentation with structural ambidexterity, i.e. reflective of a management approach that considers exploration and exploitation as activities to be separated rather than potentially integrated, and thus, implicitly, as an organisational dilemma rather than a duality. That risks are associated with structural ambidexterity is hinted at briefly as employees reflected on the 'them and us' issue - this requires effort by management on integrating processes and systems to overcome the potential for isolation. For the company this did not become an issue as the dual structures were abandoned and the company reverted to monodextrous innovation, this time exploration, as a problematic, confusing and paradoxical experience for all concerned, liberating because it is really all about the games, not about the end, but problematic because all was at risk even if not everybody saw that (The stuff we are working on is great It's all original stuff and there's no real commercial drive behind it).

The main paradox lies in the fact that as the entire company switched to exploration activities, the organisational context assumed the characteristics of an exploitation-oriented organisation whereas retrospectively at least - the previous exploitation phase was felt to contain far more features of a creativity conducive organisational context Thus there was now much greater emphasis on task accomplishment than individual innovation, on more formal and centralised structure than non routine tasks, on more uni-directional communication than on shared and horizontal flows of communication, and on outcomes rather than on creative process, all organisational factors which are closer to exploitation than exploration (Pandey and Sharma, 2009). Characteristics of a "creative organisation" which, in combining hard and soft, stretch and discipline, trust and support, affords contextual ambidexterity seemed to recede as the organisation embarked on its most creative projects ever.

Ambidexterity, structural and contextual, would have been 'best' - but difficult to achieve. The company's trajectory was 'teleological' in its focus on IP as the industry's ultimate imperative. This might have increased the 'monodextrous' mindset that focused on efficiencies first, and thus underestimated the need to balance contextual or structural (or both) aspects conducive to an innovation approach that enables the experience of the exploration/exploitation binary as a seamless coevolution, alternation, or process rather than as a momentous and surprising rupture.

\section{Conclusion: Limitations and Further Research}

A single case study has limitations in terms of generalisability, and our contribution thus lies in suggesting new areas for research rather than in confirming existing views. Ambidexterity is not a given, and how organisations learn - or do not learn - to achieve this balancing act needs further elaboration, in SMEs, industry specific settings, and combining broader literatures and multiple units of analysis.

\section{References}

AMABILE, T.M., Conti, R., Coon, H., Lazenby J., Herron M. (1996). Assessing the work environment for creativity. Academy of Management Journal, 39(5), II54II84.

ANDRIOPOULOS, C., Lowe, A. (2000). Enhancing organisational creativity: the process of perpetual challenging. Management Decision, 38(10), 734-742.

ANTCLIFF, V., Saudry, R., Stuart, M. (2005). Freelance worker networks in audio-visual industries. Lancashire Business School Working Papers. University of Central Lancashire, Preston.

BANKS, M., Calvey, D., Owen, J., Russell, D, W. (2002). Where the art is: defining and managing creativity in new media SMEs. Creativity and Innovation Management, II, 25I-260.

BARON, A. (200I), Preface. In: Swart, J., Kinnie, N., Purcell, J. People and Performance in Knowledge-Intensive Firms. CIPD, London. 
BECK, U., Bonss, W., Lau, C. (2003). The Theory of Reflexive Modernization: Problematic, Hypotheses and Research Programme. Theory, Culture \& Society, 20, I-33.

BENNER, M. J., Tushman, M. L. (2003). Exploitation, exploration and process management: the productivity dilemma revisited. Academy of Management Review, 28(2), 238-256.

BILTON, C., Cummings, S. (2010) Creative Strategy: Reconnecting Business and Innovation. John Wiley and Sons, Chichester.

BILTON, C., Leary, R. (2002). What can managers do for creativity? Brokering creativity in the creative industries. International Journal of Cultural Policy, 8(I), 4964.

BILTON, C. (2007). Management and Creativity: from Creative Industries to Creative Management. Blackwell, London.

BIRKINSHAW, C. B., Gibson, J. (2004). 'Executive briefing: The ambidextrous organisation' AIM Stage 3. http://www.aimresearch.org/publications/ambidexterous rpt.pdf [Accessed 06/06/2008]

BODEN, M., ed. (1994). Dimensions of Creativity. MIT Press/Bradford Books, Cambridge, MA, London.

BOLIANO, E. S. (2008). A Framework for Analysis of Ambidexterity and Performance in Small-to-MediumSized Firms. DLSU Business \& Economics Review, 17(I), 99-110.

BROWN, S. L., Eisenhardt, K. M. (1997). The art of continuous change: Linking complexity theory and timepaced evolution in relentlessly shifting organizations. Administrative Science Quarterly, 42, I-34.

BRYMAN, A. (2004). Social Research Methods. Oxford University Press, Oxford.

CADIN, L., Guérin, F. (2006). 'What can we learn from the video games industry? European Management Journal. 24(4), 248-255.

CADIN, L., Guérin, F., deFillipi, R. (2006). HRM practices in the video game industry: industry or country contingent? European Management Journal, 24(4), 288-298.

CHASTON, I. (2008). Small creative industry firms: a development dilemma? Management Decision, 46(6), 819831 .

CHRISTOPHERSON, S. (2004). The divergent worlds of new media: how policy shapes work in the creative economy. Review of Policy Research, 2 I (4), 543-558.

COFFEY, A., Atkinson, P. (1996). Making Sense of Qualitative Data: Complementary Research Strategies. Sage Publications, London.

COLLINS, J.C., Porras, J.I. (1997). Built to Last: Successful Habits of Visionary Companies. Harper Business, New York.

CRESWELL, J. W., Plano Clark, V. (2007). Designing and Conducting Mixed Methods Research. Sage Publications, London.

CUMMINGS, A., Oldham, G. (1997). Enhancing creativity: managing work contexts for the high potential employee. California Management Review, 40(I), 22-38.

CUMMINGS, L. (1965). Organizational climates for creativity. Academy of Management Journal, 8(3), 220-227.

DAVID, M., Sutton, C. (2004). Social Research: The Basics. Sage Publications, London.

DEBONO, E. (1993). Serious Creativity: Using the Power of Lateral Thinking to Create New Ideas, Harper Collins Business, London.

DEPEUTER, G., Dyer-Witheford, N. (2009). A playful multitude? Mobilising and counter-mobilising immaterial game labour. fibreculture, 5. Multitudes, creative organisation and the precarious condition of new media labour. http://journal.fibreculture.org/iisue5/depeuter dyerwitheford-print.html [Accessed 7/07/2009].

DENZIN, N. K., Lincoln, Y. S. (2008). Strategies of Qualitative Inquiry (3rd ed). Sage Publications, Thousand Oaks, CA. 
EDWARDS, T., Delbridge, R., Munday, M. (2005). Understanding innovation in small and medium-sized enterprises: a process manifest. Technovation, 25, 1119II 27.

EHIN, C. (2008). Unmanaging knowledge workers. Journal of Intellectual Capital, 9(30), 337-350.

EISENHARDT, K. M., Martin, J. A. (2000). Dynamic capabilities: what are they? Strategic Management Journal, $21(10 / 11), 1105-1121$.

EKOS Consultants (2009). Internationalisation in Digital Media: A Briefing Paper. Registered Office, Glasgow.

EKVALL, G. (1997). Organisational conditions and levels of organisational creativity. Creativity and Innovation Management, 6, 195-205.

GIBSON, C. B., Birkinshaw, J. (2004). The antecedents, consequences, and mediating role of organizational ambidexterity. Academy of Management Journal, 47(2), 209-226.

GOSHAL, S., Bartlett, C. A. (1997). The Individualized Corporation: A Fundamentally New Approach to Management. Harper Paperback, London.

GRABHER, G. (2004). Learning in projects, remembering in networks? Communality, sociality, and connectivity in project ecologies. European Union and Regional Studies, 2, 103-123.

GUETTEL, W. H., Konlechner, S. W. (2009). Continually hanging by a thread: Contextually ambidextrous organizations. Schmalenbach Business Review, |49-|7|.

GUETTEL, W. H., ,Konlechner, S. W. (2007). Dynamic capabilities and competence obsolescence: empirical data from research-intensive firms. Proceedings of OLKC 2007 - “Learning Fusion”, 357-374.

HE, Z, L.., Wong, P., K. (2004). Exploration vs exploitation: an empirical test of the ambidexterity hypothesis. Organization Science, 15(4), 4I8-494.

HOOGSTRATEN, T. (2005) Difference in growth between successful, unsuccessful and non-innovating SMEs, 2nd
Twente Student Conference on IT, Enschede 21 January, 2005.

KIM, W. C., Mauborgne, R. (2004). Value innovation: the strategic logic of high growth. Harvard Business Review, July-August 2004, I-I I.

ISAKSEN, S., Tidd, J. (2006). Meeting the Innovation Challenge: Leadership for Transformation and Growth. John Wiley and Sons, Chichester.

JANSEN, J., Van Den Bosch, F. A. J., Volberda, H. W. (2006). Exploratory Innovation, Exploitative Innovation, and Performance: Effects of Organizational Antecedents and Environmental Moderators (14, 2006, 08). ERIM Report Series Reference No. ERS-2006-038-STR.

KAARBO, J., Beasley, R. (1999). A practical guide to the comparative case study method in political psychology. Political Psychology, 20, 369-391.

LITTLE, S., Ray, T., eds (2005). Managing Knowledge. $2^{\text {nd }}$ ed., Sage, London.

LIU, W. (2006). Knowledge exploitation, knowledge exploration, and competency trap. Knowledge \& Process Management, 13(2), |44-16I.

MARCH, J.G. (1991). Exploration and exploitation in organisational learning. Organization Science, 2(I), $7 \mathrm{I}-87$.

MUMFORD, M.D. (2000). Managing creative people: strategies and tactics for innovation. Human Resource Management Review, 10(3), 313-35I.

MUMFORD, M.D., Gustafson, S.B. (1998). Creativity syndrome: integration, application and innovation. Psychological Bulletin, 103, 27-43.

MUMFORD, M.D., Scott, G.M., Gaddis, B., Strange, J.M. (2002) Leading creative people: orchestrating expertise and relationships. The Leadership Quarterly, 13, 705-750.

NESTA (2008a). Unlocking the potential of innovative firms. Policy Paper, NESTA Policy and Research Unit, London.

NESTA (2008b). Raise the Game: The Competitiveness of the UK's Games Development Sector and the Impact of 
Governmental Support in Other Countries. Games Investor Consulting (December 2008).

NESTA (2009). It's Time to Play: A Survey on the Impact of a Tax Credit for Cultural Video Games in the UK Development Sector. Games Investor Consulting Limited (August 2009).

NONAKA, I., Toyama, R. Konno, N. (2000). SECl, Ba and leadership: a unified model of dynamic knowledge creation. Long Range Planning, 33(I), 5-34.

NOOTEBOOM, B. (2000) Learning and Innovation in Organisations and Economie. Oxford University Press, Oxford.

MILLER, D. (1993). The architecture of simplicity. Academy of Management Review, I8(I), II6-138.

OLDHAM, G.R. and Cummings, A. (1996). Employee creativity: personal and contextual factors at work. Academy of Management Journal, 39(30), 607-634.

O'REILLY, C., Tushman, M. (2007). Ambidexterity as a dynamic capability: resolving the innovator's dilemma. Stanford University Graduate School of Business Research Paper No. 1963, I-60.

PANDEY, S., Sharma, R. R. K. (2009). Organizational factors for exploration and exploitation. Journal of Technology Management Innovation, 4(I), 48-58.

PATTON, E., Appelbaum, S.H. (2003). The case for case studies in management research. Management Research News, 26(5), 60-7I.

PRICEWATERHOUSECOOPERS (2008). Global Entertainment and Media Outlook 2008-20I2.

RANDLE, K., Rainnie, A. (2007). Managing creativity, maintaining control: a study in pharmaceutical research. Human Resource Management Journal, 7(2), 32-46.

QUINN, J. B., Baruch, J. J., Stein, K. A. (1997). The Innovation Explosion. Free Press, New York.

RAISCH, S. (2008). Balanced structures: designing organizations for profitable growth. Long Range Planning, 4I, 483-508.
RAISCH, S., Birkinshaw, J., Probst, G., Tushman, M.L. (2009). Organizational ambidexterity: balancing exploitation and exploration for sustained performance. Organization Science, 20(40), 685-695.

SCOTTISH ENTERPRISE TAYSIDE (2010). Research Interviews. Transcribed by authors. Dundee.

STENMARK, D. (2000). The role of intrinsic motivation when managing creative work. Proceedings of ICMIT 2000. IEEE Press, Singapore.

SIGGELKOW, N. (200I). Change in the presence of fit: the rise, the fall and the renaissance of Liz Claiborne. Academy of Management Journal, 44, 838-657.

STRAUSS, A. (1987). Qualitative Analysis for Social Scientists. Cambridge University Press, Cambridge.

SYDOW, J., Staber, U. (2002). The institutional embeddedness of project networks: The case of content production in German television. Regional Studies, 36(3), 215-227.

TEECE, D.J., Pisano, G., Shuen, A. (1997). Dynamic capabilities and strategic management. Strategic Management Journal, 18, 509-533.

TEECE, D. J. (2006). Explicating dynamic capabilities: The nature and microfoundations of (sustainable) enterprise performance. Haas School of Business Working Paper, Dec. 22.

TUSHMAN, M.L., O'Reilly, C.A. (1996). The ambidextrous organization: managing evolutionary and revolutionary change. California Management Review, $38(4)$, I-23.

UTTERBACK, J. M. (1994). Mastering the Dynamics of Innovation: How Companies Can Seize Opportunities in the Face of Technological Change. Harvard University Press, Boston.

YIN, R.K. (1984). Case Study Research - Design and Methods. Sage Publications, Beverley Hills.

YIN, R, K. (2009). Case Study Research - Design and Methods. Sage Publications, Beverley Hills. 
ZACKARIASSON, P., Wilson, T.L. (2007). Competition and competitiveness in the video game industry. Paper presented to the American Society for Competitiveness Conference 2007.

\section{About the Authors}

Professor Sabine Hotho is Professor of Strategic and Change Management at Dundee Business School, University of Abertay Dundee. Her research interests include change and innovation management and the management of professionals in the public and private sector. She is currently leading a research project concerned with change management practices in the new creative industries.

Dr. Katherine Champion was a research assistant at the Dundee Business School, University of Abertay Dundee. Her main research interests include creative clusters and urban development. 